\title{
JOSÉ SARAMAGO: UM OLHAR SOBRE A GLOBALIZAÇÃO E A SOCIEDADE DA INFORMAÇÃO JOSÉ SARAMAGO: GLOBALIZATION AND INFORMATION SOCIETY
}

\author{
Maria Irene da Fonseca e Sá \\ Universidade Federal do Rio de Janeiro
}

\begin{abstract}
Increasing production capacity with higher quality has been developed in an accelerated manner and technologies have constantly generated new consumer products. It is true that globalization benefited by the progress and development of technologies, leads to increased productivity and economic growth, but it can also cause unwanted effects on the income distribution of the population. Thus, social inequality generated by globalization and the power shift to whom has access to information are current challenges, which are discussed in various works of Saramago. With his parables and fables, Saramago guides his readers through the reflection on the role played by human beings in a globalized world. The research aimed to look at some of the works of José Saramago, quotes that refer to the discussion of globalization in information society. This work uses qualitative research desing in which publications on the topic of globalization are considered and analyzed. Saramago, through his novels, seeks to make his readers to question themselves and question the world in which they live.
\end{abstract}

Keywords: José Saramago, Globalization, Information Society, Information and Communication Technology, World.

\section{RESUMO}

A capacidade de produzir cada vez mais e com mais qualidade está acelerada e, a cada momento, as tecnologias geram novos produtos de consumo. É certo que a globalização propiciada pelo progresso e evolução das tecnologias provoca o aumento da produtividade e o crescimento econômico, mas também pode provocar efeitos não desejados sobre a distribuição de renda da população. Assim, a desigualdade social gerada pela globalização e o deslocamento do poder para quem detém o acesso à informação são desafios atuais e que são discutidos em várias obras de Saramago. Com suas parábolas e fábulas, Saramago encaminha seus leitores para a reflexão sobre o atuar do ser humano num mundo globalizado. A pesquisa teve por objetivo buscar, em algumas das obras de José Saramago, citações que remetam à discussão da globalização na Sociedade da Informação. $O$ trabalho vale-se da pesquisa qualitativa em que são consideradas e analisadas publicações relativas ao tema "globalização". Saramago, através de seus romances, busca fazer com que seus leitores se questionem e

Manuscript first received/Recebido em: 10/01/2016 Manuscript accepted/Aprovado em: 12/06/2016

Address for correspondence / Endereço para correspondência

Maria Irene da Fonseca e Sá, Pós-doutora em Ciências da Comunicação e Informação - Universidade do Porto, Portugal Doutora em Ciência da Informação - Universidade Federal do Rio de Janeiro, Brasil Mestre em Engenharia de Sistemas e Computação, COPPE/UFRJ, Brasil

Professor Adjunto da Faculdade de Administração e Ciências Contábeis Universidade Federal do Rio de Janeiro E-mail mariairene@ facc.ufrj.br 
questionem o mundo em que vivem.

Palavras-chave: José Saramago, Globalização, Sociedade da Informação, Tecnologias de Informação e Comunicação, Mundo.

\section{INTRODUÇÃO}

O cenário atual, descrito por vários autores como a Sociedade da Informação, se originou no momento da globalização e da acelerada disponibilização das Tecnologias de Informação e Comunicação (TIC), com destaque para a internet (Castells, 2010; Dupas, 2011).

Os momentos de mudança na sociedade estão ligados à capacidade do homem de inventar ferramentas/procedimentos/tecnologias que o auxiliem nas tarefas de seu dia a dia, facilitando sua relação com o ambiente em que vive. Entretanto, segundo Castells (2010, p. 43), não é a sociedade quem determina "o curso das transformações tecnológicas" e nem a tecnologia determina a sociedade; ambas estão integradas em uma interação dialética, onde a sociedade, apesar de não determinar a tecnologia, é capaz de exercer poder sobre ela sufocando-a ou utilizando-se dela, de forma que o destino da economia, do militarismo ou outro aspecto social possa ser mudado.

Sem dúvida, a habilidade ou inabilidade de as sociedades dominarem a tecnologia e, em especial, aquelas tecnologias que são estrategicamente decisivas em cada período histórico, traça seu destino a ponto de podermos dizer que, embora não determine a evolução histórica e a transformação social, a tecnologia (ou sua falta) incorpora a capacidade de transformação das sociedades, bem como os usos que as sociedades, sempre em um processo conflituoso, decidem dar ao seu potencial tecnológico (Castells, 2010, p. 44).

Desta forma, essa integração causa pontos a serem destacados ao longo da história da humanidade, em um processo que não depende apenas da criação de uma tecnologia, mas da capacidade da sociedade em dominá-la.

A sociedade da informação tem seu nascedouro no fim dos anos 1960, quando surgem tecnologias revolucionárias que permitem uma maior flexibilização e reorganização do trabalho. Assim, Dupas (2011, p.100) afirma:

O capitalismo global caracteriza-se por ter na inovação tecnológica um instrumento de acumulação em nível e qualidade infinitamente superiores aos experimentados em suas fases anteriores; e por utilizar-se intensamente da fragmentação das cadeias produtivas propiciada pelos avanços das tecnologias da informação.

Neste cenário, a capacidade de produzir cada vez mais e com mais qualidade está acelerada e a cada momento as tecnologias geram novos produtos de consumo e, como diz Dupas (2011, p. 49): "[...] a utopia dos mercados livres e da globalização torna-se a referência". E, ainda: 
A capacidade de produzir mais e melhor não cessa de crescer. Paciência que tal progresso traga consigo regressões, desemprego, exclusão, pauperização, subdesenvolvimento. A distribuição de renda piora, a exclusão social aumenta, o trabalho se torna mais precário nesse mundo de poder, produção e mercadoria (Dupas, 2011, p. 50).

Assim, ele alerta que "o deslumbramento diante da novidade tecnológica e a ausência total de valores éticos que definam limites e rumos poderão estar incubando tanto novos deuses, que conduzirão a humanidade à sua redenção, como serpentes cujos venenos ameaçarão sua própria sobrevivência”. (Dupas, 2011, p. 103).

Quanto à globalização, Rodrik (2011, p.11) afirma que não é a primeira vez que se experimenta um mercado global.

Quando as ferrovias e os navios a vapor baixaram o custo do transporte e a Europa partiu para o livre-comércio no final do século XIX, ocorreu uma convergência dramática nos preços das commodities (Williamson, 1996). Os fluxos de mão de obra eram também consideravelmente mais altos na época, pois milhões de imigrantes partiram do Velho para o Novo Mundo.

Canclini (2007, p. 241) fala das TIC e do impacto delas na sociedade, ressaltando as diferenças dos seres humanos:

A expansão mais ou menos uniforme e mundial de "próteses tecnológicas" (computadores e programas, telefones celulares, CDs, cartões de crédito) não elimina a diversidade das relações sociais entre as pessoas, destas com o conhecimento, com o dinheiro e com seu corpo. Sem dúvida, contribui para estabelecer relações entre os estilos de vida e de representação da vida. Mas persistem as diferenças, as divergências, as discrepâncias.

Portanto, é certo que a globalização propiciada pelo progresso e evolução das tecnologias provoca o aumento da produtividade e o crescimento econômico, mas também pode provocar efeitos não desejados sobre a distribuição de renda da população, na medida em que alguns se tornam mais capazes de se apropriar do excedente do que outros. Assim, a desigualdade social gerada pela globalização e o deslocamento do poder para quem detém o acesso à informação são desafios atuais e que, de alguma forma, são discutidos em várias obras de Saramago.

José Saramago, critico e céptico quanto ao ser humano, alerta que: “[...] as boas coisas para uns precisamente têm os seus poréns para outros [...]", (Saramago, 2006, p. 91), no livro A Jangada de Pedra, e "Se o negócio é bom ou mau, isso depende, que o dinheiro não tem sempre o mesmo valor, ao contrário dos homens, que sempre valem o mesmo, tudo e coisa nenhuma" (Saramago, 2011a, p. 107), no romance Memorial do Convento, e, ainda "O mundo não tem mais problemas que os problemas das pessoas" (Saramago, 2002, p. 40), no livro O Homem Duplicado. Assim, com suas parábolas e fábulas, Saramago encaminha seus leitores para a reflexão sobre o atuar do ser humano num mundo globalizado. 
“[...] porquê nunca houve uma greve numa fábrica de armamento[...]”, (Saramago, 2014c, p. 59). Foi a motivação para Saramago iniciar a escrever um novo livro Alabardas, Alabardas, Espingardas, Espingardas - que ficou inacabado ao falecer, em junho de 2010, mas o que ficou escrito já faz o que pensar sobre a condição humana e a banalidade da violência na sociedade contemporânea.

Todos os países, quaisquer que sejam, capitalistas, comunistas ou fascistas, fabricam, vendem e compram armas, e não é raro que as usem contra os seus próprios naturais. [...] É assim, mas não o deveria ser. [...] Não temos outro mundo (Saramago, 2014c, p. 29).

Soares faz a análise sobre o tema do livro Alabardas, Alabardas, Espingardas, Espingardas:

Armas são o ponto mais impermeável ao humanismo. Que joia da coroa do capitalismo globalizado seria mais vulnerável à crítica radical? Em nenhum outro lugar, fora da produção e do comércio de armas, o interesse econômico revela com tamanho despudor sua natureza selvagem, expondo em carne viva sua torpeza, ostentando, em suas virtudes - produtividade, eficiência, competência, inteligência, sofisticação, conhecimento, alcance, precisão - o horror, a maximização ilimitada do horror (Soares, 2014, p. 82).

Assim, o tema da pesquisa foi Saramago, de forma a buscar em algumas de suas obras citações que remetam à discussão da globalização na Sociedade da Informação.

\section{METODOLOGIA}

Para tratar o tema proposto, o trabalho, do ponto de vista da forma de abordagem do problema, vale-se da pesquisa qualitativa em que são consideradas e analisadas publicações relativas ao tema "globalização". Quanto ao objetivo é pesquisa exploratória por buscar proporcionar maior familiaridade com o tema, de forma a tornálo mais explícito. Quanto aos procedimentos técnicos envolve a análise de diversas publicações, especialmente do escritor português José Saramago.

Neste tipo de pesquisa, o pesquisador é o principal instrumento da coleta de dados. Os métodos da pesquisa qualitativa são subjetivos, indutivos, usam teoria fundamentada, empregam instrumentos que produzem informação linguística (como observações), os resultados são reportados em frases e o projeto de pesquisa é adaptado através do processo de pesquisa.

\section{RESULTADOS}

A visão de Saramago sobre a sociedade atual não é boa. A frase "O caos é uma ordem por decifrar" (Saramago, 2002, p. 103), que está no livro O homem duplicado, resume um mundo e uma sociedade onde as relações humanas são desprovidas de razão e de ética. O ponto central de seus romances é o homem e suas relações com o 
semelhante, ou seja o olhar o "outro" - a alteridade. "Ah, este mundo a que alguns chamam cão. Os cães, decerto lhe chamariam homem.” (Saramago, 2010, p. 113).

O próprio Saramago fala de sua preocupação com o mundo: "A partir de Ensaio sobre a Cegueira passei a escrever, de uma forma mais atenta, sobre o mundo em que vivemos, quem somos, em que nos transformamos." (Saramago, 2004 como citado em Aguilera, 2010, p. 328).

Em 9 de outubro de 1998, a Academia Sueca comunicou a atribuição do Prêmio Nobel da Literatura a José Saramago "que, com parábolas portadoras de imaginação, compaixão e ironia torna constantemente compreensível uma realidade fugidia" (Nobel Prize, 1998).

Assim, a Academia Sueca atribui o termo "parábola" aos romances de Saramago. Segundo o Dicionário Koogan/Houaiss (1997, p. 1204), parábola é "Comparação desenvolvida em pequeno conto, no qual se encerra uma verdade, um ensinamento." Portanto, há que buscar nos romances de Saramago as verdades (pois não existe uma única) e os ensinamentos (que também são vários).

Saramago disse em 1986: "Sou ateu com uma atitude religiosa e vivo muito em paz." (Aguilera, 2010, p. 36). Assim, como Jesus, gostava de falar por parábolas. Na Bíblia Sagrada, os quatro evangelistas afirmam que Jesus usava parábolas para transmitir ensinamentos. "E Jesus falou para eles muita coisa com parábolas [...] (Mateus, 1990, p. 1255). "Jesus lhes perguntou: "Vocês não compreendem essa parábola?" (Marcos, 1990, p. 1286). "Então Jesus contou-lhes esta parábola [...]" (Lucas, 1990, p. 1334). "Jesus contou-lhes essa parábola, mas eles não entenderam o que Jesus queria dizer.”, (João, 1990, p. 1369). Nas palavras dos evangelistas percebe-se que as parábolas nem sempre alcançavam o seu propósito, ou seja, nem sempre o povo e os discípulos entendiam os ensinamentos que Jesus pretendia lhes passar. Da mesma forma, as parábolas (os romances) de Saramago, nem sempre são bem entendidos ou não alcançam o objetivo que o escritor teve ao pensá-lo e escrevê-lo.

Porém, no livro Discursos de Estocolmo, da Fundação José Saramago, é afirmado que:

Os seus trabalhos literários podem ser interpretados como alegorias que apresentam perspectivas subversivas sobre factos históricos, ou que criam, a partir de situações impossíveis, realidades que tratam de explicar o mundo em que vivemos, este mundo em que o ser humano não é a prioridade absoluta, como o escritor não se cansava de repetir.

Segundo o Dicionário Koogan/Houaiss (1997: 48), "alegoria" é "Expressão de uma ideia através de uma imagem, um quadro, um ser vivo etc.; obra literária ou artística que utiliza esta forma de expressão [...]". É o que os romances de Saramago buscam comunicar. Através de histórias, personagens e suas falas, o autor pretende levar o leitor a compartilhar de suas ideias e verdades. Saramago (2002, p. 81) no livro $O$ Homem duplicado, lembra: "Houve já quem afirmasse que todas as grandes verdades são absolutamente triviais e que teremos de expressá-las de uma maneira nova e, se 
possível, paradoxal, para que não venham a cair no esquecimento." Porém, nem sempre a humanidade está pronta a aceitar as trivialidades, ou em outras palavras, a simplicidade. John Maeda, em seu livro As leis da simplicidade: design, tecnologia, negócios, vida, afirma que "Tecnologia e vida somente tornam-se complexas se você permitir" (2007, p. 99) e que "O conhecimento torna tudo mais simples" (2007, p. 33). Pode-se citar também Paulo, em sua carta aos Coríntios, "Posso fazer tudo o que quero. Sim, mas nem tudo me convém" (1990, p.1466). Portanto, as alegorias de Saramago servem para que o leitor perceba a realidade simples e trivial e se aproveite dela ou não.

Lopes (2010, p. 139-140) corrobora: "Numa visão de conjunto, o traço dominante mais inovador parece confluir para o fato de estarmos agora diante de alegorias que funcionam como distopias de um mundo abandonado pela razão". E ainda, segundo o próprio Saramago, A caverna, Todos os nomes e Ensaio sobre a cegueira formariam uma "trilogia involuntária" na base do mesmo caráter alegórico, pessimista e desencantado de romances sobre um mundo abandonado pela razão" (Lopes, 2010, p. 158).

Há quem fale de metáforas e fábulas na obra de Saramago. Aguilera (2014, p. 74) fala de Saramago: "Suas fabulações pensavam e faziam pensar, até se postularem, metaforicamente, como uma espécie de ensaios com personagens".

De acordo com Koogan/Houaiss (1997, p. 1069), metáfora é o "Processo pelo qual se transfere a significação própria de uma palavra para outro significado que lhe convém apenas em virtude de uma comparação mental [...]" e fábula é "Apólogo, conto alegórico geralmente em versos, tem como personagens quase sempre animais e como objetivo uma lição de moral" (1997, p. 655). Nesse contexto, segundo Lopes (2010, p. 159), o romance $O$ homem duplicado, assim como A caverna, traz a preocupação “[...] com o caráter ilusório da realidade virtual, da imagem sobrepondo-se à realidade. Ambas as obras são como metáforas para a alienação dos seres humanos diante do mundo e de si mesmos devido à interposição de coisas mercantilizadas e desprovidas das relações sociais de trabalho criado pelo poder demoníaco do dinheiro".

Praxedes (2008) fala sobre o romance Ensaio sobre a cegueira de Saramago:

No romance Ensaio sobre a cegueira (1995), de José Saramago, a cegueira descrita é representada através de inúmeras metáforas. Já no início da narrativa as personagens são acometidas pelo chamado "mal branco", impossível de ser diagnosticado como um dos tipos já conhecidos de cegueira. Considerando a cegueira como metáfora, ao longo deste romance Saramago tenta explicar como as pessoas vão se tornando cegas no mundo contemporâneo, como inexplicavelmente ocorreu com o primeiro cego, primeira personagem apresentada na narrativa, que cegou quando conduzia o seu automóvel: de repente a realidade tornou-se indiferenciada à sua volta.

Arnaut (2012) identifica três momentos na obra de Saramago:

Cumpre relembrar, a propósito, e de acordo com uma breve mas necessária contextualização, que o primeiro ciclo de produção literária saramaguiana decorre entre Manual de Pintura e Caligrafia (1977) e 
Ensaio Sobre a Cegueira (1995), exclusive. Neste período verificamos uma enorme apetência pelo tratamento de temas históricos, directa ou indirectamente relacionados com a História e com a Cultura portuguesas, seja de um passado mais remoto seja de um tempo mais recente. [...] O segundo ciclo, por conseguinte, abarca os romances publicados entre Ensaio Sobre a Cegueira e As Intermitências da Morte, exclusive. A delimitação feita no âmbito desta fase dos romances de teor universal ou universalizante diz respeito quer à utilização de estratégias que evidenciam o culto de temas de cariz mais geral, quer a uma reconhecida ressimplificação da linguagem e da estrutura da narrativa (Saramago, apud Reis, 1998, p. 43; Arnaut, 2008, p. 40-43).

$\mathrm{Na}$ reescrita da História Portuguesa ou na escrita, por vezes prospectiva, da História da Humanidade (as duas, violações aos mais elementares direitos do Homem, ora alertando para os perigos resultantes afinal, sempre e inevitavelmente interligadas), o narrador tem permanentemente por objectivo a exposição clara de preocupações de teor humanista e humanitário, ora denunciando as da globalização, de complicados jogos políticos e/ou religiosos, ou de sistemas repressivos que transformam o Homem em criatura aviltante.

No caso dos romances que compõem, por enquanto, o terceiro ciclo de produção ficcional, [...] propomos designar como "romances fábula", julgamos que a linha diferencial relativamente aos anteriores se instaura, por um lado, a partir de novas ressimplificações. [...]A diferença substancial que lemos em As Intermitências da Morte, A Viagem do Elefante e Caim é relativa, sim, por outro lado, ao tom marcadamente cómico e à cor, agora mais suave, a que o narrador/autor recorre para construir a acção, os temas que a percorrem e as personagens que lhe dão vida.

Eco (2009, p. 14) utiliza os quatro termos, e outros, para falar da obra de Saramago:

[...] que na sua crítica moral e social nunca leva o problema a peito, mas poeticamente o contorna nos modos do fantástico e do alegórico, de modo que o seu leitor (embora suspeitando que de te fabula narratur) terá de pôr muito de si para compreender até onde vai parar o apólogo [...] E este escritor fantasioso e metafórico [...] E este delicado tecelão de parábolas [...].

Conclui-se que, sendo parábolas, alegorias, fábulas ou metáforas, a obra de Saramago faz uso de diferentes e diversos recursos para levar suas mensagens ao leitor e é o próprio Saramago que afirma “[...] dependendo mais do leitor do que da leitura, embora esta em tudo dependa daquele, por isso nos é tão difícil saber quem lê o que foi lido e como ficou o que ficou lido por quem leu [...]", (Saramago, 2006, p. 71), o que significa dizer que cada leitor faz uma leitura e esta é particular dependendo das caraterísticas do ser humano que é cada leitor.

E Saramago diz que é uma necessidade dele expor os problemas que observa no 
mundo e que ao falar deles busca explicações para si próprio:

Embora uma fábula normalmente contenha uma lição de moral, não é a minha intenção com meus livros. Na verdade, diante de determinado tema, eu trato-o como se precisasse de chegar a uma conclusão para uso próprio. No fundo, são questões que tenho com o mundo, com a sociedade, com a nossa história. [...] É como se o mundo me incomodasse no sentido mais profundo e eu, através de um romance ou fábula, o deixasse exposto. (Saramago, 2005 como citado em Aguilera, 2010, p. 329-330).

Assim, alguns dos romances (parábolas, alegorias, fábulas ou metáforas) de Saramago pretendem levar os leitores à reflexão sobre o mundo em que vivemos e, especialmente, fazê-los pensar e considerar o fenômeno da globalização.

\subsection{Ensaio sobre a cegueira}

A irracionalidade do mundo contemporâneo foi a mola propulsora para o desenvolvimento desse romance. O Ensaio sobre a Cegueira pode ser considerado um romance cruel, com descrição de episódios que remetem às necessidades básicas do ser humano, e provavelmente, ao que há de pior no ser humano. Saramago, nos Cadernos de Lanzarote (2011b), utiliza diferentes vocábulos para o referenciar: "a cegueira da razão", "o uso irracional da razão", "Tempo de cegos". Talvez o que melhor caracteriza o romance é "desconcertos do mundo".

A cegueira alcança a todos, com exceção de uma única personagem que procura se manter racional. De início, vem o internamento num manicômio dos que perderam a visão, mas, em seguida, todos ficam cegos e a cidade entra num estado de degradação total, com todo tipo de exploração: física, sexual, econômica, moral. Desta forma, Saramago nos apresenta a sociedade globalizada em que vivemos, com todos os tipos de exploração.

Pilar, esposa de Saramago, em outubro de 2008 quando do lançamento do filme sobre o livro, fala do romance lançado em 1995:

No meu entender, o livro antecipou os efeitos da crise que estamos a sofrer. As pessoas, desesperadas, correndo por Wall Street, de banco em banco antes que o dinheiro se acabe, não são outras que as que se movem, cegas, sem rumo, no romance e agora no filme. A diferença é que não têm uma mulher do médico que as guie, que as proteja. (Saramago, 2009a, p.91).

No mesmo ano, Saramago, em conjunto com outras pessoas, subscreveu um protesto de forma a alarmar a sociedade quanto à crise e às possíveis saídas que se afiguravam. Segue um trecho do manifesto:

As "leis do mercado" conduziram a uma situação caótica que levou a um "resgate" de milhares de milhões de dólares, de tal modo que, como se referiu acertadamente, "se privatizaram os ganhos e se nacionalizaram as perdas”. Encontraram ajudas para os culpados e não para as vitimas. Esta é uma ocasião única para redefinir o sistema económico mundial a favor da justiça social.

Não havia dinheiro para os fundos de combate à SIDA, nem de 
apoio para a alimentação no mundo... e afinal, num autêntico turbilhão financeiro, acontece que havia fundos para que não se arruinassem aqueles mesmos que, favorecendo excessivamente as bolhas informáticas e imobiliárias, arruinaram o edifício económico mundial da "globalização".

[...] Investimentos nas energias renováveis, na produção de alimentos (agricultura e aquicultura), na obtenção e condução de água, na saúde, educação, habitação... para que a "nova ordem económica", seja, por fim, democrática e beneficie as pessoas. O engano da globalização e da economia de mercado deve terminar! A sociedade civil já não será um espectador resignado e, se necessário for, utilizará todo o poder de cidadania que hoje, com as modernas tecnologias de comunicação, possui. (Saramago, 2009a, p.94).

Sobre o livro Ensaio sobre a cegueira, Nestrovski (1995) fala que: "É uma visão das trevas, uma viagem ao inferno, e a história de uma resistência possível à violência dos tempos escuros". E continua:

Às vésperas do fim do milênio, num período onde imperam, de um lado, a velocidade, a ganância e a abstinência moral e, de outro, a profecia e um misticismo compensatórios, o escritor vem nos lembrar a "responsabilidade de ter olhos quando os outros os perderam". É um livro, então, sobre a ética, e é um livro também sobre o amor, e sobre solidariedade. "Parece uma parábola", comenta alguém no romance; mas sua força, como nas melhores parábolas, vem precisamente do realismo e da descrição, no limite do inominável.

$\mathrm{O}$ autor sofre! E sofrem os leitores ao se identificarem num mundo decadente e cruel, corroído pela falta de moral, pelo egoísmo, pela falta de solidariedade, pelo valor do imediato, pelo coração de pedra dos personagens, pela maldade, pela exacerbação do eu. Foi globalizada a cegueira, no entanto o que sobressai do cenário descrito é a individualidade, a satisfação do "eu" em detrimento do "outro".

Lopes (2011, p. 108) fala do sofrimento do narrador: "Ao Expresso, por exemplo, referiria que: "O tempo da escrita, sobretudo nos últimos tempos, foi de sofrimento, de momentos em que me sentia incapaz de aguentar aquilo que estava a escrever [...]. Foi como se tivesse dentro de mim uma coisa feia, horrível, e tivesse que sacá-la. Mas não saiu, está no livro e está dentro de mim" (28 de outubro de 1995)." E está dentro de cada ser humano. Aguilera (2010, p. 154) relata: "Há uma personagem [a rapariga dos óculos escuros] no meu livro [Ensaio sobre a Cegueira] que pronuncia as palavras-chave: "Dentro de nós há uma coisa que não tem nome. É isso que somos." O que precisamos é procurar dar um nome a essa coisa: talvez, simplesmente, lhe possamos chamar 'humanidade"'.

Falando de cegos, Saramago (2011b, p.17) comenta:

[...] no tempo do franquismo, um notável do regime [...] sugeriu ao governo a construção duma cidade destinada exclusivamente a cegos. A ideia não foi por diante, mas é fácil perceber quão fecunda 
era de possibilidades: depois dessa primeira experiência talvez começasse a haver cidades de surdos, cidades de coxos, cidades de manetas, cidades de gagos, cidades de mudos, cidades de mongoloides, cidades de paraplégicos, cidades de epilépticos, e com a continuação e o êxito da prática segregativa, acabaríamos fatalmente por construir cidades para velhos, cidades para loucos, cidades para enfermos em fase terminal, enfim, para quantos se configurassem como elementos perturbadores do viver da comunidade dos normais.

Aqui cabe a reflexão sobre: "Quem são os normais?"; "Será que todos e cada ser humano não é portador de algum tipo de deficiência?"; "Será que de alguma forma essa segregação, descriminação, não está presente no mundo contemporâneo?"; "Quem são os Diferentes, Desiguais e Desconectados de Canclini (2007)?”. Portanto, “[...] Penso que não cegámos, penso que estamos cegos, Cegos que vêem, Cegos que, vendo, não vêem" (Saramago, 1995, p.310). Há urgência em combater a cegueira!

E Saramago explica o andamento do romance:

A cegueira desaparece porque nunca tinha sido uma verdadeira cegueira. As personagens viveram uma experiência em que o uso racional da razão as conduzira a extremos de violência e de crueldade semelhantes aos que hoje vemos e vivemos em todo mundo. O meu romance [Ensaio sobre a Cegueira] espelha o horror comtemporâneo, não é mais duro que a realidade que nos rodeia. Falta perguntarmos porque no livro não o digo - se a experiência vivida pelas minhas personagens os mudou ou não. Eu sou muito céptico, porque penso que os seres humanos não aprendem nada com as experiências que fazem. O Médico do romance no fim coloca a hipótese de as pessoas na realidade terem sido ou não sempre cegas. Dizendo, com isso, algo semelhante ao que acontece hoje: não vemos quem está à nossa volta, não somos capazes de nos preocupar com as relações com os outros seres humanos. (Saramago, 1996 como citado em Aguilera, 2010, p. 314-315).

Ele também encaminha os leitores para a reflexão sobre a compreensão do mundo que estamos a viver, com todos os tipos de exclusão e extorsão:

[...], no fundo, trata-se da visão como entendimento, como capacidade de compreender. E ao perder a visão, nesse sentido metafórico, o que uma pessoa perde é a capacidade de compreender. Estamos a perder a capacidade de nos relacionarmos, de respeitarmos o outro na sua diferença, seja ela qual for. E depois tudo isto, que já não é só o ser humano individual reconvertido ao que chamamos puros instintos. É toda uma cidade que retrocede ao instinto, que eu não chamaria puro, porque o que aparece todas as vezes, e o que lá aparece é a violência, a extorsão, a tortura, o domínio de uns pelos outros, a exploração. (Saramago, 2002 como citado em Aguilera, 2010, p. 327)

Saramago usa o livro para expor o incomodo que o mundo lhe causa, pois " [...] a dignidade do ser humano é todos os dias insultada pelos poderosos do nosso mundo, 
que a mentira universal tomou o lugar das verdades plurais [...]”, (Saramago, 1998, p. 20). E ele afirma, falando do romance que escreveu: "É o mundo que existe. Não há nada no livro que não possa ser encontrado no mundo real", (Saramago, 2015, p. 32).

\subsection{A caverna}

Na parábola social A Caverna, Saramago traz sua crítica para a sociedade de espetáculos que se cristaliza no poder das novas tecnologias e nos grandes centros comerciais, em que o ser humano não perde o emprego mas a função. É a sociedade da exibição na qual prevalecem os verbos comprar e vender.

É um romance que fala de mudanças e de como as mudanças são percebidas e assimiladas pelo ser humano:

[...] são os tempos que mudam, são os velhos que em cada hora envelhecem um dia, é o trabalho que deixou de ser o que havia sido, e nós que só podemos ser o que fomos, de repente percebemos que já não somos necessários no mundo, se é que alguma vez o tinhamos sido antes, mas acreditar que o éramos parecia bastante, parecia suficiente, e era de certa maneira eterno pelo tempo que a vida durasse [...] (Saramago, 2000, p.106-107).

O que se sabe não serve mais! "Trabalhas, trabalhas e trabalhas, e um dia [...] dizem-te que o que fizeste não serviu para nada" (Saramago, 2000, p. 43). "Como é que uma pessoa se prepara para levar uma martelada na cabeça" (Saramago, 2000, p. 42).

Nunes (2000) afirma: “A anulação do trabalho manual ou artesanal pela tecnologia, tal poderia ser o resumo desse aspecto destrutivo do capitalismo em seu acme, convertido pelo romance numa parábola social, a que o romancista contrapõe, em sutil paródia, o mito dos que crêem nas sombras."

Saramago reflete sobre a insegurança vivida pelos seres humanos no mundo atual:

Quando às vezes eu digo que $A$ Caverna é um romance sobre o medo, temos de entender o que é que quero significar com isso: um medo que mais ou menos sempre sofremos, mas não tanto como agora. É o medo de perder o emprego. Há um medo instalado na sociedade moderna, talvez pior que todos os outros medos: é o medo da insegurança, o medo de amanhã não ter com que alimentar a família. Esse medo paralisa. (Saramago, 2001, como citado em Aguilera, 2010, p.326)

Lopes (2011: 111-112) também fala do livro:

O livro viria efectivamente a contrastar a absolutização do mercado no símbolo do centro comercial e a do consumidor no lugar do cidadão com uma família de oleiros artesanais que acaba por conseguir subtrair-se à lógica concentracionista do neoliberalismo. Nem todos são devorados na voragem mercantilista, consumista e reprodutora do "pensamento único". A opacidade da cidadania 
transformada em imagem das coisas que se podem comprar e vender, qual uma nova "caverna" platônica que a impedisse de ver o eu e o outro em relações de solidariedade humana por fora das alienações coisificadas, é transportada nesta nova alegoria saramaguiana.

Assim, o próprio Saramago diz:

O centro [comercial] é um lugar de ideologia. É isso que leva as pessoas ao centro comercial. Os que dizem que as ideologias acabaram, na realidade o que estão a dizer é que acabou "uma" ideologia. Não é verdade que as pessoas não tenham uma ideologia. Mas é nova: consumir, consumir. Antes comprávamos, agora consumimos. (Saramago, 2001, como citado em Aguilera, 2010, p. 488)

Portanto, é importante refletir sobre o significado dos verbos comprar e consumir. Enquanto o verbo comprar tem como significado "adquirir a preço de dinheiro" (Koogan/Houaiss, 1997: 415), o verbo consumir tem o significado de "gastar, despender, extinguir" (Koogan/Houaiss, 1997, p. 430). Desta forma, precisa-se comprar, adquirir, aquilo que se necessita para viver, mas consumir é ir além: é comprar por comprar...

O romance $A$ Caverna leva os leitores à realidade de uma caverna moderna, um lugar sem correntes, mas onde o homem vive amarrado, preso, enjaulado... Um mundo onde não há espaço para o desenvolvimento de atividades artesanais. Uma realidade em que o novo totalitarismo se baseia na economia e nas multinacionais, os novos donos do mundo. Assim, o mais descartável que existe na atualidade é o ser humano.

Canclini alerta para os problemas que advêm com a globalização:

As investigações sobre cidades globais vêm revelando, junto com os sistemas de integração (forte papel das empresas transnacionais, misturas culturais, crescente número de turistas), a exclusão de zonas tradicionais e pobres, o aumento da marginalização, do desemprego e da insegurança. Coexistem oportunidades de incorporação global e movimentos de degradação. As fraturas entre integrados e excluídos, conectados mundialmente e localizados à força não são exclusivas dos países subdesenvolvidos; encontram-se e agravam-se também nas urbes européias e estadunidenses." (Canclini, 2007 p. 252).

E Saramago enfatiza: "A mim, o que me interessa é que o centro comercial simboliza um sistema cruel. Fabrica excluídos sem piedade alguma” (Saramago, 2001, como citado em Aguilera, 2010, p. 326). E afirma:

O problema que se coloca é: que tipo de vida queremos? O único lugar público seguro que existe é o centro comercial, como antes era o parque, a rua, a praça. [...] O centro comercial é a nova catedral e a nova universidade: ocupa o espaço de formação da mentalidade humana. Os centros comerciais são um símbolo. Não 
tenho nada contra eles, o que estou é contra uma forma de ser, de um espírito quase autista de consumidores obcecados pela posse de coisas. É aterradora a quantidade de coisas inúteis que se fabricam e se vendem, e o Natal é uma ocasião estupenda para comprovar isso." (Saramago, 2001, como citado em Aguilera, 2010, p. 487-488).

A família de oleiros se recusa a aceitar a realidade do centro comercial. Assim, renasce a esperança, voltada para casos isolados e não como fenômeno social, ressaltando o pessimismo do autor que está descrente da humanidade e que afirma "A beleza do mundo futuro pouco nos importa se não estivermos nele" (Saramago, 2014d: 112).

\subsection{O Homem duplicado}

Em 2002, Saramago publica o romance $O$ Homem Duplicado, cerca de dois anos após a publicação do romance $A$ Caverna, que mantém a preocupação com o mundo globalizado, com a sociedade do exibicionismo, com a cultura do descartável e com a alienação do ser humano. Enquanto no romance $A$ Caverna, a crítica estava no centro comercial e no ser humano consumidor, no romance $O$ Homem Duplicado é apresentado um ser humano incapaz de se ver no próximo, em que o 'eu' fica ameaçado pela presença do 'outro'.

Sobre $O$ homem duplicado, Lopes afirma:

De certa maneira, esse novo romance prolongava a preocupação do anterior com o carácter ilusório da realidade virtual, da imagem sobrepondo-se à realidade. Ambas as obras são como que metáforas para a alienação dos seres humanos face ao Mundo e a si mesmos devido à interposição de coisas mercadorizadas e desprovidas das relações sociais de trabalho criador pelo poder demoníaco do dinheiro. Antes o símile platónico da caverna corporiza-se no centro comercial e no cidadão tornado consumidor. Agora Maximiliano Tertuliano Afonso era incapaz de se rever no seu duplo António Claro e a sua identidade ficava ameaçada pela presença do "outro" (Lopes, 2011, p. 111-112).

Portanto, enquanto o mundo se globaliza através de uma cultura geral (moda, música, costumes ...), o ser humano não se vê no seu igual, ou melhor, não aceita o outro igual a si.

É uma metáfora para a alienação do ser humano. Pode-se usar a mesma roupa, as mesmas marcas, ouvir e cantar a mesma música, fazer as mesmas coisas, ter os mesmos hábitos..., mas ter a mesma aparência não é aceitável. Nesse romance, não há lugar para a solidariedade que pode transformar a realidade. Pelo contrário, fica explicita a agressividade da humanidade num mundo em que cada vez mais se deterioram as relações entre os seres humanos.

Saramago ressalta o seu objetivo ao escrever o romance $O$ homem duplicado: 
O que no fundo eu quero tratar [em $O$ Homem Duplicado] é o tema do "outro". Se o "outro" é como eu, e o "outro" tem todo o direito de ser como eu, eu pergunto-me: até que ponto eu quero que esse "outro" entre e usurpe o meu espaço? Nesta história, o "outro" tem um significado que nunca antes teve. Actualmente, no mundo, entre "eu" e o "outro" há distâncias e não é possível superar essas distâncias, e, por isso, o ser humano cada vez consegue menos chegar a um acordo. As nossas vidas são compostas em cerca de $95 \%$ pela obra dos outros. No fundo vivemos num caos e não existe uma ordem aparente que nos governe. Então a ideia-chave no livro é que o caos é um tipo de ordem por decifrar. Com este livro proponho ao leitor que investigue a ordem que existe no caos. (Saramago, 2007, como citado em Aguilera, 2010, p. 333).

Assim, no romance $O$ Homem Duplicado, Saramago dá continuidade à analise das transformações por que passa a humanidade na era da Informação. Em Ensaio sobre a Cegueira, os seres humanos perdem a visão numa alegoria em que a sociedade parece estar cega e não percebe os desconcertos do mundo. Em A Caverna, a família de oleiros perde sua função na sociedade de consumo, incapazes de sobreviver à sociedade de consumo, mas não perde a esperança. Em O Homem Duplicado, há a perda da identidade, numa sociedade informatizada, que vai perdendo suas singularidades e cultura para um padrão global.

É Saramago (2002, p. 80) que lembra:

[...] falar de um presente que a cada minuto nos rebenta na cara, falar dele todos os dias do ano ao mesmo tempo que se vai navegando pelo rio da História acima até às origens, ou lá perto, esforçar-nos por entender cada vez melhor a cadeia de acontecimentos que nos trouxe aonde estamos agora, isto é outro cantar, dá muito trabalho, exige competência na aplicação, há que manter sempre a corda tensa, sem quebra.

É a discussão da alienação do ser humano face ao mundo. “[...] a descoberta casual que conduz ao encontro dos sósias não desemboque na produção de relações intersubjectivas de solidariedade e comunhão rumo a uma outra metrópole, mas acabe apenas por confirmar a opacidade e a agressividade urbanas." (Lopes, 2011, p. 113)

Assim, a frase "O caos é uma ordem por decifrar" (Saramago, 2002, p. 103) resume um mundo e uma sociedade onde as relações humanas são desprovidas de razão e de ética.

E Saramago discorre sobre a globalização de sentimentos:

Deixando agora de lado se deveríamos ou não envergonhar-nos de ser a espécie a que pertencemos aquilo que é, ao menos envergonhemo-nos das nossas apatias, das nossas indiferenças, das nossas cumplicidades tácitas ou abertas, das nossas penosas cobardias disfarçadas de neutralidade. Já que os poderes do mundo se mostram tão empenhados em globalizar-nos, globalizemo-nos nós por nossa 
conta... (Saramago, 2011b, p. 233).

\subsection{As intermitências da morte}

Em 2005, é publicado o romance As intermitências da morte, uma discussão filosófica sobre a morte. No romance, com certo humor, é discutida a greve da morte durante um certo período de tempo, em determinado lugar, e os diversos problemas que tal fato provoca na sociedade envolvida com a sobrecarga de seres humanos inválidos para sempre, que necessitam de cuidados e provocam gastos, mas que não produzem. É a discussão da morte, ou da falta dela, no plano social e pessoal.

O próprio Saramago discorre sobre o livro:

[...] tomei a morte como tema de uma reflexão mais profunda. No livro, uso primeiro uma grande angular e crio uma fantasia em torno de uma suposição: como a ausência da morte afectaria uma sociedade inteira? Depois, fecho a objectiva para um caso específico: a morte materializa-se em personagem e tenta carregar para o além um violoncelista que insiste em não morrer. Procuro demonstrar que a morte é fundamental para o equilíbrio da natureza. (Saramago, 2005, como citado em Aguilera, 2010, p. 330)

Lopes insere o livro na coleção de livros de Saramago que levam à reflexão sobre o mundo e os problemas da atualidade:

As Intermitências da Morte não são alheias à reconfiguração alegórica das redes de iniquidades e cumplicidades que os governos, as empresas, as religiões e as associações ilegais têm mais ou menos conscientemente estabelecido no Mundo concreto para o domínio neoliberal da sociedade e o enfraquecimento das funções do Estado (Lopes, 2011, p. 113).

Saramago enfatiza essa visão: "Disse para mim: vamos falar da vida de hoje através da morte: do funcionamento dos políticos, dos idosos atirados para lares, do egoísmo, da sensualidade..." (Saramago, 2005, como citado em Aguilera, 2010, p. 331). E, complementa: "Porque gastamos tanto tempo a perguntar o que há além da vida? Se nos interrogássemos sobre o que realmente se está a passar aqui na vida, no tempo que nos calhou." (Saramago, 2005, como citado em Aguilera, 2010, p. 331).

Portanto, Saramago, através da greve da morte, encaminha os leitores para a análise de como este mundo, em que se vive, funciona: os idosos que ao final de sua vida são confinados em asilos perdendo contato com seus familiares e não recebendo deles os cuidados necessários; as empresas cujo lema é a produtividade, o ganho, não se peocupando com o ser humano; os representantes do governo sempre objetivando ganhos pessoais e a próxima eleição; as associações ilegais que sempre surgem em momentos de desventura e que servem para, em sua grande maioria, explorar ou tirar benefícios dos menos afortunados e até as religiões que pregam a caridade, mas que não a praticam. E tudo está globalizado! Em todas as partes do mundo acontecem, mais ou menos, os mesmos fatos: a mesma ganância, a mesma falta de caridade, as mesmas 
iniquidades, as mesmas maldades...

Lopes ressalta a preocupação de Saramago com a postura do ser humano e da sociedade quanto à morte, mas coloca o próprio Saramago no centro da discussão da morte como questão básica da existência humana: “[...] o essencial talvez seja agora uma parábola sobre a condição humana de "ser para a morte" e uma convivência salutar de um escritor octogenário com o ocaso da existência numa perspectiva filosófica de materialismo dialéctico", (Lopes, 2011, p. 117).

E Saramago conclui sobre o livro e sobre a morte:

Viver eternamente seria estar condenado a uma velhice eterna. Salvo se o tempo parasse. E isso não está no livro. Mas teria também efeitos perversos. No fundo, o livro [As Intermitências da Morte] empurra uma porta aberta. Diz aquilo que todos já sabemos: que temos que morrer. Mas talvez mostre, com mais clareza, que temos que morrer para viver. Se não, a vida seria insuportável (Saramago, 2005, como citado em Aguilera, 2010, p. 331-332).

Enfim, "Viver eternamente nunca podia ser uma coisa boa" (Saramago, 2005, como citado em Aguilera, 2010, p. 183), principalmente no mundo atual.

\section{CONSIDERAÇÕES}

Saramago, através de seus romances, busca fazer com que seus leitores se questionem e questionem o mundo em que vivem:

A pergunta que devíamos colocar-nos é: O que é que eu fiz se nada mudou? Deveríamos viver mais no desassossego. $\mathrm{O}$ amanhã não acontecerá se não mudarmos o hoje. Como se conta em A Caverna, tudo o que levamos às costas na vida são vésperas e todas essas vésperas, incluindo a desesperança, a desilusão, são as que influenciam o amanhã. É preciso fazer o trabalho todos os dias com as mãos, a cabeça, a sensibilidade, com tudo (Saramago, 2000, como citado em Aguilera 2010, p. 371).

A quem interessa a globalização presente no mundo atual? Quem são os beneficiados? Segundo Saramago:

No fundo a globalização é um totalitarismo soft, isto é, prometenos tudo, vende-nos a sua felicidade e cria necessidades que não tínhamos. É uma forma de domínio político, mas os cidadãos não se apercebem ou não encontram forma de reagir (Saramago, 2006, como citado em Aguilera, 2010, p.458).

Da mesma forma como Saramago apresenta a sociedade globalizada no romance A caverna, Dupas discorre sobre a sociedade contemporânea:

De fato, a vida nas sociedades contemporâneas se apresenta como uma imensa acumulação de espetáculos. Tudo o que era vivido 
diretamente torna-se uma representação. Sob todas as suas formas particulares - informação ou propaganda, publicidade ou consumo de divertimentos - o espetáculo constitui o modelo atual da vida dominante na sociedade. A primeira fase da dominação da economia sobre a vida social acarretou uma degradação do "ser" para o "ter". Em seguida, operou-se um deslizamento generalizado do "ter" para o "parecer-ter". $\mathrm{Na}$ atual situação das grandes massas excluídas da sociedade global só resta o "identificar-se-com-quem-parece-ser-outer" por meio do espetáculo, sequer ao vivo, mas "visto-a-distância" através das mídias globais que lhes oferecem exibições instantâneas de todos os tipos e partes do mundo (Dupas, 2011, p.52)

Neste contexto, Saramago discorre sobre as verdadeiras necessidades de globalização da sociedade:

Se amanhã me disserem que vão globalizar o pão não encontrareis globalizador mais entusiasta que eu. E se me disserem - e o fizerem - que vão globalizar tudo quanto milhares de milhões de seres humanos estejam a precisar para viver dignamente, então garanto-vos que me vereis convertido num fanático dela. Mas a globalização está a acrescentar miséria à miséria, fome à fome, exploração à exploração (Saramago, 2004, como citado em Aguilera, 2010, p. 456).

E aponta para a contradição da globalização. Estamos a cada dia mais próximos de tudo e de todos através do uso das TIC, especialmente, da internet. No entanto cada vez mais isolados do convívio humano, como fica claro ao se lerem os seus romances.

[O mundo do fim do milênio é] um mundo com duas tendências contraditórias: a globalização e a fragmentação. Um homem está em sua casa, afastado de todo o contacto humano, podendo chegar pelo computador, o modem, o fax, a todos os lugares. Cada vez mais perto de tudo e mais longe de tudo. A tecnologia permite-nos ter tudo dentro de casa sem sair dela. E, se eu não estiver satisfeito com a realidade, posso viver noutra realidade, a virtual (Saramago, 1995, como citado em Aguilera, 2010, p. 480)

E ele conclui: "[A globalização], por um lado, fragmenta tudo o que tem a ver com a vida das pessoas, mas por outro lado concentra tudo o que a organiza." (Saramago, 2001, como citado em Aguilera, 2010, p. 489). Dupas (2011, p.51) corrobora dizendo que "no mundo global, os poderes que atuam sobre o destino individual estão mal identificados, ocultos pelas redes multinacionais e pelas grandes organizações internacionais. Esse mundo-espetáculo no qual as vedetes são as figuras do ganhador, do ostentador - e seus palcos eletrônicos -, mitifica o fugaz e o frágil". É neste mundo globalizado que o indivíduo tem sua vida tornada pública e a liberdade de consciência mutilada:

Acabou-se a privacidade. Se de alguma forma a vida privada acabou, a consciência privada, para usar o mesmo termo, sofreu um 
atentado semelhante. A liberdade, e agora falo da liberdade de consciência, às vezes arrisca-se a converter-se numa coisa utópica, com muito pouco conteúdo (Saramago, 2005, como citado em Aguilera, 2010, p.495)

Quanto à evolução das TIC e ao progresso proporcionado, Dupas enfatiza que:

Não se trata de ir contra o desenvolvimento tecnológico, adotando um posicionamento reacionário. A questão é bem outra: a tecnologia pode e deve se submeter a uma ética que seja libertadora a fim de contemplar o bem-estar de toda a sociedade, presente e futura, e não apenas colocar-se a serviço de minorias ou atender necessidades imediatas" (Dupas: 2011, p. 18).

Saramago, consciente da evolução tecnológica e de suas aplicações, utilizou as TIC em seu trabalho de escritor. Em 25 de novembro de 2008, ele escreve em seu blog:

[...] a muitos jornalistas interessava-lhes a minha decisão de escrever na "página infinita da internet". Será que, aqui, a bem dizer, nos assemelhamos todos? É isto o mais parecido com o poder dos cidadãos? Somos mais companheiros quando escrevemos na internet? Não tenho respostas, apenas constato as perguntas. E gosto de estar escrevendo aqui agora. (Saramago, 2009a, p. 121).

Ao se utilizar da ferramenta de blog, Saramago mantém aquilo que sempre foi marca de sua obra e de sua postura pública: a indignação frente à injustiça e a divulgação de suas opiniões. Em 2009, a atividade diária do blog dá origem às publicações $O$ Caderno e $O$ Caderno 2. Eco, no prefácio de $O$ caderno 2, diz: “[...] que é o impulso de irritação, a dica satírica, a chicotada crítica escrita à pressa, que fornecerá a seguir o material para uma reflexão ensaística ou narrativa mais desenvolvida. É a escrita diária que inspira as obras de maior empenho, e não o contrário", (Eco, 2009, p. 18).

Quanto aos fracassos do mundo globalizado, eles são também apontados por Canclini (2007, p. 260):

Os fracassos parecem mais fáceis de perceber e documentar no campo socioeconômico (concentração de renda, aumento do desemprego, queda dos salários, colapso de empresas e países) e no político (proliferação de conflitos, desprestígio acelerado de governantes e instabilidade social).

E também por Dupas (2011, p. 17): "Nesse mundo de poder, produção e mercadoria, o progresso traz consigo desemprego, exclusão, concentração de renda e subdesenvolvimento." E, mais enfaticamente: "O resultado na rede é zero: os perdedores pagam pelos ganhadores.”, (Dupas, 2011, p. 43).

Assim, Saramago exclama:

Como se pode dizer que a globalização traz benefícios quando 
são os seus próprios teóricos que reconhecem que estão a produzir-se desigualdades terríveis. A globalização não vai resolver os problemas mundiais, pode é resolver os problemas de uma determinada camada da população mundial. Mas seguramente que não são os três mil milhões de pessoas que vivem com dois dólares por dia (Saramago, 2001, como citado em Aguilera, 2010, p. 489)

Como apreciado nas fábulas de Saramago, a globalização procura impor uma cultura global em detrimento das diversas culturas locais. Canclini ressalta a importância da convivência da cultura global com as características das culturas locais:

Surge, então, a pergunta sobre se seremos capazes de construir uma ordem intercultural globalizada na qual as dimensões sociais, econômicas, políticas e culturais se reorganizem a fim de que aprendamos a descobrir o valor do diferente, a reduzir a desigualdade que converte as diferenças em ameaças irritantes e a gerar conexões construtivas à distância [...] (Canclini, 2007, p. 268).

Saramago explora o assunto, afirmando: "O problema não está em sermos diferentes. Está em que, quando falamos de diferenças, de diferentes, estamos involuntariamente a introduzir um outro conceito, o conceito de superior e de inferior. É aí que as coisas se complicam", (Saramago, 1998, como citado em Aguilera, 2010, p. 484), e mais enfaticamente, declara: "Nenhum país tem o direito a apresentar-se como guia cultural dos restantes. As culturas não devem ser consideradas melhores ou piores, todas elas são culturas e basta." (Saramago, 1998, como citado em Aguilera, 2010, p.482). Torna-se necessário que cada povo se conscientize da força de seus valores culturais.

Atualmente, a informação circula amplamente através das redes. Qualquer cidadão, de qualquer parte do mundo e a qualquer momento, pode ter acesso a ela. Dupas afirma que: "A informação tem se convertido em um componente indispensável da reprodução econômica e dos ganhos de competitividade", (Dupas, 2011, p. 41). Porém, não é necessário possuir a informação, mas ter acesso a ela. No entanto algumas questões surgem a partir deste cenário: "Está o cidadão preparado para discernir sobre a informação que está acessando?"; "O cidadão possui recursos (tecnológicos, financeiros, culturais) para acessar a informação?’. Saramago fala sobre estas questões:

O excesso de abundância de informação pode fazer do cidadão um ser muito mais ignorante. Eu explico. Acho que as possibilidades tecnológicas para desenvolver a massificação da informação têm sido muito rápidas. No entanto, o cidadão não dispõe dos elementos e da formação adequados para saber escolher e selecionar, o que leva a que ande perdido nessa selva. Precisamente, nesse desnível é onde se dá a instrumentalização em prejuízo do indivíduo e, portanto a desinformação (Saramago, 2004, como citado em Aguilera, 2010, p. 465).

Saramago resume as preocupações que externou em seus romances, acreditando no poder do conhecimento: 
Toda a minha obra pode ser entendida como uma reflexão sobre o erro. Sim, sobre o erro como verdade instalada e por isso suspeita, sobre o erro como depuração intencional de factos, sobre o erro como ilusão dos sentidos e da mente, mas também sobre o erro como ponto necessário para se chegar ao conhecimento (Saramago, 2001, como citado em Aguilera, 2010, p. 325).

E, assim, em alguns dos romances, a esperança está presente ao final das fábulas de Saramago.

No Ensaio sobre a cegueira, os cegos voltam a ver e o médico, após a cegueira, tem a compreensão do ocorrido: "Penso que não cegámos, penso que estamos cegos, Cegos que vêem, Cegos que, vendo, não vêem" (Saramago, 1995, p. 310). É a vitória do conhecimento. No romance $A$ caverna, a família de oleiros se rebela contra a vida presente, representada pelo centro, e vai em busca de um futuro longe da caverna: é a liberdade, a busca de outra vida. No livro As intermitências da morte, o amor vence a morte.

Entretanto, na fábula $O$ homem duplicado o igual se repete, dissolvendo a singularidade numa sociedade globalizada. "O caos é uma ordem por decifrar" (Saramago, 2002, p. 103) e assim o ser humano tem um longo caminho de aprendizado pela frente.

Saramago, sempre pessimista, lembra: "[...] Espero que nos tornemos a ver alguma vez, e em dias mais felizes, se ainda os houver; Pelos vistos perderam-se pelo caminho [...] (Saramago, 2014b, p. 350).

\section{REFERÊNCIAS}

Aguilera, F.G. (2010). José Saramago nas suas palavras. (2a ed.). Alfragide, Portugal: Caminho.

Aguilera, F. G. (2014). Um livro inconcluso, uma vontade consistente. Em Saramago, J. Alabardas, alabardas, espingardas, espingardas. São Paulo, Brasil: Companhia das Letras.

Arnaut, A. P. (2012). Novos rumos na ficção de José Saramago: os romances fábula (As Intermitências da Morte, A Viagem do Elefante, Caim). Disponível em: http://www.ufjf.br/revistaipotesi/files/2012/03/6-novos-rumos-na-

fic\%C3\%A7\%C3\%A3o.pdf. Acesso em: 03 ago. 2015.

Canclini, N. G. (2007). Diferentes, desiguais e desconectados: mapas da interculturalidade. Tradução Luiz Sérgio Henriques. 2a ed. Rio de Janeiro, Brasil: Editora UFRJ.

Castells, M. (2010). A sociedade em rede - A era da informação: economia, sociedade e cultura. Tradução Roneide Venancio Majer. 6a ed. São Paulo, Brasil: Paz e Terra.

Dupas, G. (2011). Ética e poder na sociedade da informação: de como a autonomia das novas tecnologias obriga a rever o mito do progresso (3a ed.). São Paulo, Brasil: Editora Unesp.

Eco, U. (2009). Um blogger chamado Saramago. Em O Caderno 2. Alfragide, Portugal: Editorial Caminho.

João (1990). Evangelho Segundo São João. Bíblia Sagrada: Edição Pastoral. São Paulo, 
Brasil: Edições Paulinas.

Koogan/Houaiss (1997). Enciclopédia e Dicionário Ilustrado. Rio de Janeiro, Brasil: Edições Delta.

Lopes, J. M. (2010). Saramago - Biografia. São Paulo, Brasil: Leya.

. (2011). Biografia - José Saramago. Lisboa, Portugal: Guerra \& Paz.

Lucas (1990). Evangelho Segundo São Lucas. Bíblia Sagrada: Edição Pastoral. São Paulo, Brasil: Edições Paulinas.

Maeda, J. (2007). As leis da Simplicidade: design, tecnologia, negócios, vida. São Paulo, Brasil: Novo Conceito Editora.

Marcos (1990). Evangelho Segundo São Marcos. Bíblia Sagrada: Edição Pastoral. São Paulo, Brasil: Edições Paulinas.

Mateus (1990). Evangelho Segundo São Mateus. Bíblia Sagrada: Edição Pastoral. São Paulo, Brasil: Edições Paulinas.

Nestrovski, A. (1995). Em Saramago, J. (1995). Ensaio sobre a cegueira. São Paulo, Brasil: Companhia das Letras.

Nobel Prize (1998). Disponível em: http://www.nobelprize.org/nobel_prizes/literature/laureates/1998/press-po.html. Acesso em: 03 ago. 2015.

Nunes, B. (2000). Em Saramago, J. (2000). A caverna. São Paulo, Brasil: Companhia das Letras.

Paulo (1990). Primeira Carta aos Coríntios. Bíblia Sagrada: Edição Pastoral. São Paulo, Brasil: Edições Paulinas.

Praxedes, W. (2008). Ensaio sobre a cegueira: a cegueira como metáfora no livro de José Saramago. Revista Espaço Acadêmico. n. 88. Disponível em: http://www.espacoacademico.com.br/088/88praxedes.htm. Acesso em: 03 ago. 2015.

Rodrik, D. (2011). A Globalização foi longe demais?. São Paulo, Brasil: Editora Unesp. Saramago, J. (1995). Ensaio sobre a cegueira. São Paulo, Brasil: Companhia das Letras.

Saramago.

(1998). Discursos de Estocolmo. Lisboa, Portugal: Fundação José (2000). A caverna. São Paulo, Brasil: Companhia das Letras. . (2002). O homem duplicado. São Paulo, Brasil: Companhia das Letras. . (2006). A jangada de pedra. São Paulo, Brasil: Companhia das Letras. . (2009a). O Caderno. Alfragide, Portugal: Editorial Caminho. . (2009b). O Caderno 2. Alfragide, Portugal: Editorial Caminho.

Caminho. (2010). Deste mundo e do outro. ( $8^{\mathrm{a}}$ ed.). Alfragide, Portugal: . (2011a). Memorial do Convento. (41a ed.). Rio de Janeiro, Brasil:

Bertrand Brasil.

Editorial Caminho.

(2011b). Cadernos de Lanzarote: Diário V. Alfragide, Portugal: (2014a). As Intermitências da morte. (3a ed.). Lisboa, Portugal: Porto Editora.

Editora. . (2014b). Ensaio sobre a Lucidez. (3a ed.). Lisboa, Portugal: Porto Brasil: Companhia das Letras. . (2014d). Os apontamentos. (4 $4^{\mathrm{a}}$ ed.). Lisboa, Portugal: Porto Editora. . (2015). Ensaio sobre a cegueira: arquitetura de um romance: notas do 
autor. Disponível em: http://recursos.bertrand.pt/recurso?\&id=10746269. Acesso em: 5 jan. 2016.

Soares, L. E. 2014. Em Saramago, J. (2014). Alabardas, alabardas, espingardas, espingardas. São Paulo, Brasil: Companhia das Letras. A violência segundo Saramago. 